\title{
1002 Women with severe ischemic cardiomyopathy have worse survival than men despite similar degree of myocardial scar: a delayed hyper-enhancement MRI study \\ Deborah H Kwon*, Carmel M Halley, Thomas P Carrigan, Victoria Zysek, Randall Setser, Zoran Popovic Paul Schoenhagen, Randall Starling, Scott D Flamm and Milind Y Desai
}

Address: Cleveland Clinic Foundation, Cleveland, OH, USA

* Corresponding author

from I th Annual SCMR Scientific Sessions

Los Angeles, CA, USA. I-3 February 2008

Published: 22 October 2008

Journal of Cardiovascular Magnetic Resonance 2008, I0(SuppI I):AI27 doi:I0.I I86/I532-429X-I0-SI-AI27

This abstract is available from: http://jcmr-online.com/content/I0/SI/AI27

(c) 2008 Kwon et al; licensee BioMed Central Ltd.

\section{Background}

Patients with severe ischemic cardiomyopathy (ICM) have reduced survival. The association between degree of scarring, gender and survival is unclear in such patients. We sought to determine, using delayed hyperenhancement magnetic resonance imaging (DHE-MRI), if female gender is associated with increased mortality in ICM patients with severe left ventricular (LV) dysfunction.

\section{Methods}

349 patients ( $24 \%$ women) with severe ICM $>/=70 \%$ stenosis in $>/=1$ epicardial vessel on angiography and mean LV ejection fraction (EF) 23\%], that underwent DHE-MRI (Siemens 1.5 T scanner, Erlangen, Germany) from 20036 were studied. DHE-MR images were obtained in standard long and short axis orientations (covering the entire LV), after injection of Gadolinium dimenglumine using an inversion recovery spoiled gradient echo sequence: TE $4 \mathrm{msec}$, TR $8 \mathrm{msec}$, flip angle 300, bandwidth $140 \mathrm{~Hz} /$ pixel, $23 \mathrm{k}$-space lines acquired every other RR-interval, field of view (varied from 228-330 in the x-direction and 260-330 in the y-direction) and matrix size (varied from 140-180 in the $\mathrm{x}$-direction and 256 in the y-direction). For DHE-MRI analysis, a custom analysis package (VPT software, Siemens, Erlangen, Germany) was used to manually delineate endocardial and epicardial myocardial edges. Scar was defined (as \% of myocardium in a 17-seg- ment model on custom software, Siemens Research) on DHE-MR images, as intensity $>2$ standard deviation above viable myocardium. Transmurality score was recorded in all segments as follows: $0=$ no scar, $1=1-$ $25 \%$ scar, $2=26-50 \%, 3=51-75 \%$ and $4=>75 \%$. Global LV scar burden was calculated as transmurality score for all segments/17. LV volumes, EF, demographic/clinical data, history of cardiac transplantation and all-cause mortality were recorded.

\section{Results}

There were 56 events ( 51 deaths and 5 cardiac transplantations) over a mean follow up $2.6 \pm 1.2$ years. Characteristics of men vs. women are shown in Table. On univariate survival analysis, women had worse outcomes, compared to men (log-rank $\mathrm{p}=0.03$ Figure 1$)$, despite similar extent of scar (Table 1).

\section{Conclusion}

In ICM patients with severely reduced LVEF, women have worse outcomes, compared to men, despite similar risk factors, LVEF, myocardial scar burden and smaller volumes. 


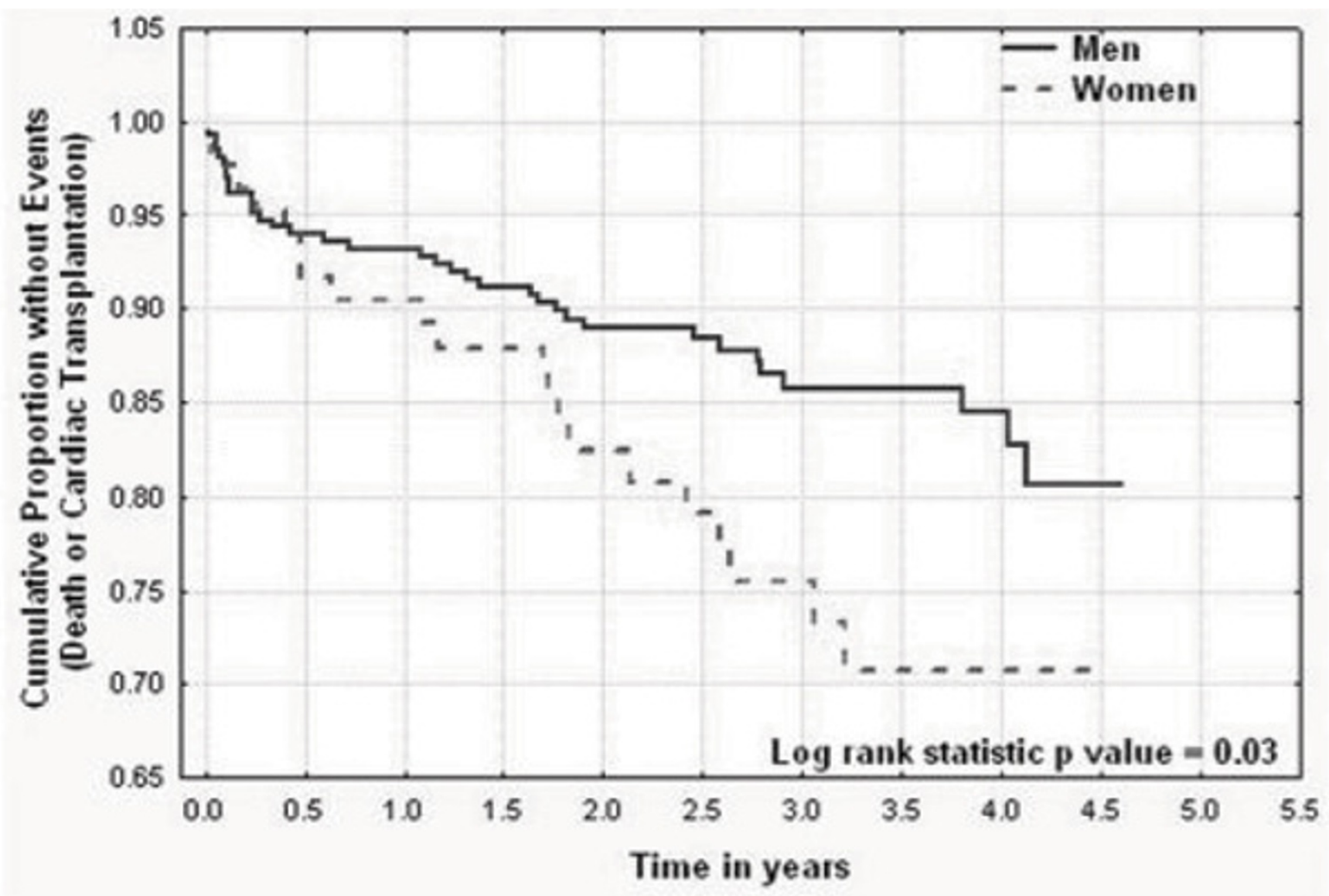

Figure I 
Table I: In ICM patients with severely reduced LVEF, women have worse outcomes, compared to men, despite similar risk factors, LVEF, myocardial scar burden and smaller volumes.

\begin{tabular}{|c|c|c|c|}
\hline Total $n=349$ & Men $(n=265)$ & Women $(n=84)$ & p-value \\
\hline Age (years) & $66 \pm 11$ & $64 \pm 12$ & 0.20 \\
\hline Diabetes Mellitus (\%) & $75(28)$ & $24(29)$ & 0.9 \\
\hline Hypertension (\%) & $93(35)$ & $34(40)$ & 0.4 \\
\hline Betablockers (\%) & $150(57)$ & $51(60)$ & 0.6 \\
\hline Angiotensin converting enzyme inhibitors(\%) & $126(48)$ & $37(44)$ & 0.6 \\
\hline Statins (\%) & $142(54)$ & $47(56)$ & 0.70 \\
\hline History of coronary artery bypass grafting & $22(8)$ & $7(8)$ & 0.9 \\
\hline LV ejection fraction (\%) & $23 \pm 8$ & $25 \pm 8$ & 0.23 \\
\hline LV enddiastolic volume (ml) & $241 \pm 107$ & $189 \pm 88$ & $<0.001$ \\
\hline LV endsystolic volume (ml) & $142 \pm 90$ & $100 \pm 68$ & 0.001 \\
\hline Mean scar \% on DHE-MRI & $32 \pm 21$ & $29 \pm 21$ & 0.39 \\
\hline $\begin{array}{c}\text { Number of segments with transmurality score } \geq 3 \text { on } \\
\text { DHE-MRI }\end{array}$ & $8.2 \pm 5$ & $7.7 \pm 5$ & 0.36 \\
\hline Global LV scar burden on DHE-MRI & $2.10 \pm 1.1$ & $2.00 \pm 1.1$ & 0.37 \\
\hline Post MRI revascularization (\%) & $72(27)$ & $17(20)$ & 0.20 \\
\hline Post-MRI ICD or CRT & $70(26)$ & $25(30)$ & 0.55 \\
\hline $\begin{array}{l}\text { Combined events (death or cardiac transplantation during } \\
\text { follow-up) (\%)* }\end{array}$ & 31 (12\%) death and 5 cardiac transplantations & $20(24)$ & 0.03 \\
\hline
\end{tabular}

DHE-MRI: delayed hyperenhancement magnetic resonance imaging, LV: left ventricle, ICD: implantable cardioverter defibrillator, CRT: cardiac resynchronization therapy

Publish with Biomed Central and every scientist can read your work free of charge

"BioMed Central will be the most significant development for disseminating the results of biomedical research in our lifetime. "

Sir Paul Nurse, Cancer Research UK

Your research papers will be:

- available free of charge to the entire biomedical community

- peer reviewed and published immediately upon acceptance

- cited in PubMed and archived on PubMed Central

- yours - you keep the copyright 